\title{
Oral Lesions Observed in Tobacco Consumers: Socio-Demographical and Clinical Aspects in the Prefectures of Kankan and Siguiri Republic of Guinea
}

\author{
Diallo Oumar Raphiou ${ }^{1}$, Conde Alhassane1, Diallo Ibrahim¹, Balde Mamadou Aliou² \\ ${ }^{1}$ Department of Odontostomatology and Maxillofacial Surgery, Donka National Hospital, Conakry, Guinea \\ ${ }^{2}$ Center for Research and Valorization of Medicinal Plants, Conakry, Guinea \\ Email: *rafioumajid@yahoo.fr
}

How to cite this paper: Raphiou, D.O., Alhassane, C., Ibrahim, D. and Aliou, B.M. (2021) Oral Lesions Observed in Tobacco Consumers: Socio-Demographical and Clinical Aspects in the Prefectures of Kankan and Siguiri Republic of Guinea. Open Journal of Stomatology, 11, 443-450.

https://doi.org/10.4236/ojst.2021.1111039

Received: August 8, 2021

Accepted: November 16, 2021

Published: November 19, 2021

Copyright $\odot 2021$ by author(s) and Scientific Research Publishing Inc. This work is licensed under the Creative Commons Attribution International License (CC BY 4.0).

http://creativecommons.org/licenses/by/4.0/

(c) (i) Open Access

\begin{abstract}
Introduction: Oral lesions observed in Chewing Tobacco (CT) consumers are histological alterations caused by direct contact with the tissues of the oral cavity. The objectives of this study were to determine the socio-demographic status of consumers and describe the clinical characteristics of the oral lesions observed. Material and Method: It was a descriptive cross-sectional study lasting 12 months (January 2017 to January 2018), in the prefectures of Kankan and Siguiri as a framework. Individuals who use chewing tobacco and whose oral examination revealed oral lesions were included in this study. Results: The frequency of oral lesions induced by the consumption of chewing tobacco was 90\%. Dental pain was the most cited reason for using CT by respondents, i.e., $25.41 \%$. The most concerned age group was that of $50-64$ years or 23.81 with a male predominance of $84.13 \%(n=53)$. A number of 61 respondents came from rural areas. Farmers were the predominant socio-professional group, i.e., $63.49 \%(n=40)$. In $60.32 \%(n=38)$ of respondents, the duration of CT consumption was greater than 10 years. Black villous tongues followed by neoplastic ulcerations were the most common oral lesions with 32 (50.79\%) and 14 (22.22\%) cases, respectively. The site of the lesion was the tongue in 47 consumers $(74.61 \%)$ and in the lower vestibule in 15 users (23.80\%). Among the oral diseases, mylolysis was the most common, i.e., 95.24\% $(\mathrm{n}=60)$. In $82.54 \%$ of cases ( $n=52)$, Simplified Oral Hygiene Index (SOHI) was low and in $12.70 \%$ $(\mathrm{n}=8)$ of respondents, SOHI was good. Conclusion: Chewing tobacco predisposes to a high risk of damage to the oral cavity and the development of potentially malignant lesions. In addition, it exerts some detrimental effects on the teeth and adjacent structures.
\end{abstract}




\section{Keywords}

Chewing Tobacco, Oral Lesions, Socio-demographic, Clinical, Guinea

\section{Introduction}

Oral lesions observed in consumers of Chewing Tobacco (CT) are histological changes produced or caused by direct contact with the tissues of the oral cavity. $\mathrm{CT}$ is one of the constituents of the smokeless tobacco group. It is a product made from a mixture of natural and chemical substances, the main active substance of which is nicotine [1]. This tobacco has a variety of names in different countries of the world: betel, paan (India, Southeast Asia, and South America); Snus (Europe); Toombak (Africa); nass, naswar (Central Asia) [2]. The consumption of CT could induce potentially malignant and cancerous lesions, periodontal disease, gingivitis, pigmentations of the mucosa, dental caries and in addition nicotine dependence [3].

The frequency of oral lesions related to the consumption of CT is variously assessed in the literature. Al-Maweri S.A. et al. [4] in Yemen, in 2014, reported 239 or $58.4 \%$ of cases of oral lesions in CT users $(\mathrm{N}=409)$. Hallikeri K. et al. [5] in India in 2018 reported $54.17 \%(n=1438)$ of individuals who developed oral lesions following regular CT consumption. The evaluation of the carcinogenic risks of CT by the International Agency for Research on Cancer (IARC) confirmed that it is carcinogenic to humans and the risk of developing oral cancer attributable to $\mathrm{CT}$ in the population is estimated at 66\% [6]. Oral cancer is responsible for more than 140,000 deaths per year worldwide. Each year, the diagnosis of oral cancer is made in more than 300,000 people [7].

Guinea is a country in West Africa where the production and consumption of CT are deeply rooted in traditions. Despite this, no study has been published in our country on the oral lesions observed in users of CT. Thus, we considered it necessary to carry out this study, the objectives of which were to describe the socio-demographic characteristics of consumers of CT, to describe the oral lesions observed in these patients.

\section{Materials and Method}

It was a descriptive cross-sectional study carried out in the prefectures of Kankan and Siguiri (Republic of Guinea), over a period of 12 months (January 2017 to January 2018).

The sampling was exhaustive and covered all people using CT encountered in the prefectures mentioned and likely to have oral lesions on clinical examination.

Individuals who consumed $\mathrm{CT}$ and in whom clinical examination revealed oral lesions at the site of CT deposition were included in this study. Consumers of CT who had oral lesions far or away from the site of CT deposition were ex- 
cluded.

The survey was carried out in two (2) stages: the first consisted of selecting the localities with high production and consumption of CT. In Kankan, the district of Djélibakoro ( $95 \mathrm{~km}$ from the city center) was selected and in Siguiri; the town center, the sub-prefectures of konomakoura, Niandankoro, Kiniebakoura, the districts of Balandougou and Falama were selected. The second stage focused on households. In collaboration with local authorities, the homes of CT consumers have been identified. A meeting with the person (s) using CT was organized at their home to explain the purpose of the study in order to obtain their voluntary adherence to the survey. An odontostomatologic examination was performed among consumers who agreed to participate in the survey.

The investigation team consisted of 3 people: an examining agent (dental surgeon): responsible for carrying out the clinical examination; a data entry operator for recording data in pre-established survey forms; a guide serving at the same time as an interpreter was recruited in each village and made available to the interviewers for support in the selected households. The clinical examination material consisted of a complete single-use examination tray, headlamp, gloves, masks and goggles.

After clinical examination, individuals who presented oral lesions at sites of CT deposition were informed of the existence of lesions and the risks associated with these lesions. A referral sheet to specialized structures was given to these individuals. People who did not have oral mucosal lesions were advice on oral hygiene and informed on the risk of developing oral cancer in connection with the consumption of CT. No biopsies or laboratory tests were performed during this study. The confidentiality of the data and the identity of the surveys were respected.

Data collection and analysis: The survey forms were completed manually when one of the respondents met our inclusion criteria. Word processing was performed using Microsoft Word software, data analysis and analysis was performed using Microsoft Excel and SPSS 21 software

\section{Results}

Out of a total of 70 individuals examined, 63 individuals or $90 \%$ had oral lesions related to the consumption of CT and 7 individuals or $10 \%$ had no lesions. In this series, 53 consumers $(84.13 \%)$ were male with a sex ratio of 5.3. The most affected age groups were 50 - 64 years with $23.81 \%$. The average age was 63 with extremes of 20 to 80 . Farmers were the most represented (63.49\%) (Table 1).

Regarding to the duration of CT consumption per year, $60.32 \%(n=38)$ of the respondents had a duration between 5 and 10 years; $23.81 \%(n=14)$ of respondents with a duration of more than 10 years. Only $15.87 \%(n=11)$ of respondents had a duration of less than 5 years. In this study, 59 of the respondents consumed CT more than 3 times per day, i.e., $93.65 \%$, and 4 respondents, or $6.35 \%$, consumed two (2) times per day. The tongue was the site of CT placement in 
$74.61 \%$ of cases $(n=47)$, followed respectively by those who put tobacco in the oral vestibule $(23.80 \% ; \mathrm{n}=15)$ (Figure 1 ) and simultaneously tongue and nostrils in 1 case (1.59\%). According to the type of mucosal lesions, black villous tongue was the most observed $50.79 \%(\mathrm{n}=32)$ followed by neoplastic ulcerations in $22.22 \%$ of cases $n=14$ (Table 2, Figure 2).

The most common dental lesions in the respondents were mylolysis with $95.24 \%$ $(n=60)$, followed by dental caries with $85.71 \%(n=54)$, periodontal disease $55.56 \%$ $(\mathrm{n}=35)$ and hypersialia with $38.09 \%(\mathrm{n}=35)$. The number of cases of neoplastic ulceration increased with age (Table 3 ).

Table 1. Distribution of respondents according to socio-demographic profile.

\begin{tabular}{ccc}
\hline Socio-demographic data & Number & Percentage (\%) \\
\hline Age (years) & 7 & 11.11 \\
\hline $20-34$ & 11 & 17.46 \\
$35-49$ & 15 & 23.81 \\
$50-64$ & 13 & 20.63 \\
$65-80$ & & \\
\hline Gender & 53 & 84.13 \\
Male & 10 & 15.87 \\
Female & & 63.49 \\
\hline Occupation & 40 & 12.7 \\
Farmer & 08 & 9.53 \\
Household & 06 & 7.93 \\
Worker & 05 & 3.17 \\
Hunter & 02 & 1.59 \\
Griot & 01 & 1.59 \\
Gold panner & 01 & \\
Trader & &
\end{tabular}

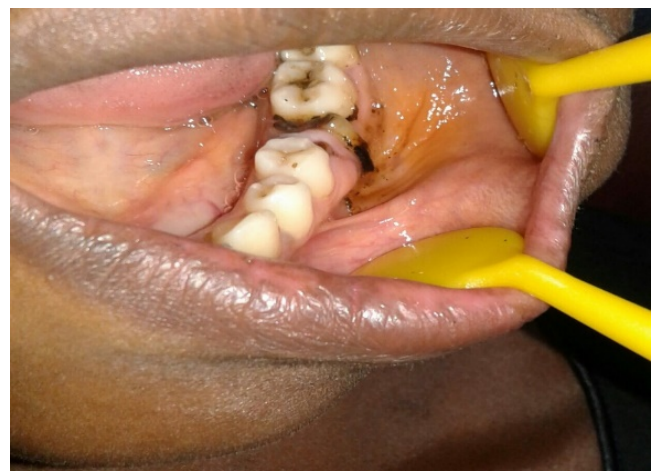

Figure 1. Leukoplakia of the vestibule and the left cheek mucosa corresponding to the area of the CT placement. 


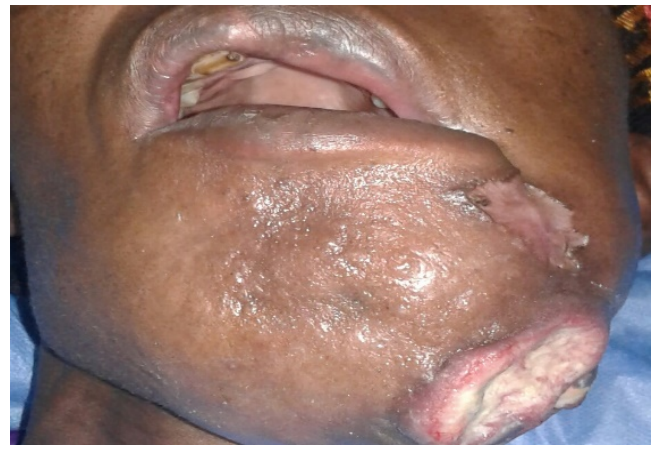

Figure 2. Neoplastic ulceration of the cheek with invasion of the mandible corresponding to the area of the CT placement.

Table 2. Type of lesion of the oral mucosa $(\mathrm{N}=63)$.

\begin{tabular}{ccc}
\hline Type of lesion of the oral mucosa & Number & Percentage (\%) \\
\hline Black villous tongue & 32 & 50.79 \\
Neoplastic ulceration & 14 & 22.22 \\
Contact ulceration & 9 & 14.29 \\
Leucoplakia & 4 & 6.36 \\
Lichen planus & 2 & 3.17 \\
Tabacco melanosis & 2 & 3.17 \\
\hline
\end{tabular}

Table 3. Distribution of respondents according to the type of lesion of the oral mucosa and age.

\begin{tabular}{cccc}
\hline Age groups & Types of oral lesions & Number of cases & Percentage \\
\hline \multirow{2}{*}{20 - 34 Years } & Tabacco melanosis & 2 & 3.17 \\
& Black villous tongue & 8 & 12.7 \\
\hline 55 - 49 Years & Oral candidiasis & 2 & 3.17 \\
& Black villous tongue & 11 & 17.46 \\
& Neoplastic ulceration & 2 & 3.17 \\
\hline $50-64$ Years & Black villous tongue & 7 & 11.11 \\
& Leukoplakia & 2 & 3.17 \\
& Contact ulceration & 5 & 7.93 \\
& Neoplastic ulceration & 8 & 12.69 \\
\hline & Neoplastic ulceration & 4 & 6.35 \\
& Leukoplakia & 2 & 3.17 \\
\hline & Black villous tongue & 6 & 9.52 \\
& Contact ulceration & 4 & 6.35 \\
\hline
\end{tabular}

Average age: 63 years; Extreme: 20 and 80 years. 


\section{Discussions}

During this study, 70 consumers of chewing tobacco were examined. Among them, 63 presented oral lesions with a frequency of $90 \%$. This result is superior to that found by Al-Maweri S.A. et al. [4] in Yemen who reported 8.9\% $(\mathrm{n}=27)$ of people who had at least one lesion of the oral mucosa following CT use. In 2018, Hallikeri K. et al. [5] in a study carried out in India had found a frequency of $54.17 \%(\mathrm{n}=1439)$ of oral lesions. Reddy S.S. et al. [8], reported $44.1 \%(\mathrm{n}=$ $398)$ of cases with oral lesions and $55.8 \%(n=503)$ of cases without lesions. The predominance of oral lesions in this series would be due to the fact that the present study was carried out in areas with high production and consumption of CT but also to the size of the sample.

A male predominance was found, 53 individuals or $84.13 \%$, with a sex ratio of 5.3. This result is comparable to that found by Shukla A. [9] in India who reported a frequency of $68.62 \%(\mathrm{n}=70)$ for men and $31.37 \%(\mathrm{n}=32)$ for women. It is superior to those of Al-Maweri S.A. et al. [4] who found a male predominance of 67.8\% versus 32.2\% female at Sanaa Hospital in Yemen in 2013.

The high frequency of men in the study may be a coincidence, as no study has demonstrated the role of gender in the pathogenesis of oral lesions observed in CT users. The ages of the patients ranged from 20 to 80 years with an average of 65 years. The 50 - 64 year old age group was the most affected with a frequency of $23.81 \%$. These results are contrary to those reported by Singh G.P. et al. [10] who found a predominance of the $21-30$ age group, i.e., a frequency of $39.4 \%$. These results could be explained by the fact that adults were more willing to perform the clinical examination. All socio-professional groups can be affected by oral lesions induced by the consumption of CT. However in this series, the growers were the most concerned with 40 consumers or $63.49 \%$ followed by housewives $(n=8) 12.7 \%$. The predominance of CT used by the less educated or illiterate segment of the population has been reported in several studies [11] [12].

In this study, 38 respondents $(60.32 \%)$ had a duration of CT consumption greater than 10 years, i.e., a frequency of $60.32 \%$. These results are similar to those reported by Agbor M.A. et al. [13] who had found that $31.1 \%$ of patients $(\mathrm{n}=37)$ had a duration of consumption greater than 10 years and for $58 \%(\mathrm{n}=$ 69) this duration was between 6 and 10 years. The main factors influencing the duration of CT consumption would be the dose-effect relationship, the lack of information of the population in disadvantaged areas on the harmful effects of $\mathrm{CT}$ and customs.

During the study period, 59 respondents or $93.65 \%$ consumed CT several times a day (more than 3 times). Agbor M.A. et al. [13] reported a frequency of daily consumption of $77.3 \%(\mathrm{n}=92)$ more than 3 times per day. The reason for consuming CT several times a day is the dependence on nicotine and the dose-effect relationship; the greater the dependence, the more frequent it is taken.

The most common oral mucosal lesions associated with CT were black villous 
tongue in 32 cases (50.79\%), followed by neoplastic ulcerations in 14 cases $(22.22 \%)$.

These results are different from those reported by Reddy S.S. et al. [8] who found mucositis to be the most frequent lesion with $59.5 \%(n=236)$, followed by submucosal fibrosis in $22.8 \%$ of cases $(n=91)$. In addition, Shukla A. [9] in 2014 , reported a high rate of submucosal fibrosis and leukoplakia with respective frequencies of $56.86 \%(n=58)$ and $19.60 \%(n=20)$. The onset and progression of oral lesions would depend on the type of tobacco product, the duration and frequency of CT use. Other factors such as the $\mathrm{pH}$ of the CT, the exposed surface, the chemical coatings, the contact time of the CT and the method of handling in the mouth could be incriminated [14]. The most common oral diseases were mylolysis 60 cases $(95.24 \%)$, followed by 54 cases $(85.71 \%)$ of dental staining and 30 cases $(47.62 \%)$ of chronic periodontal disease.

These results are comparable to those reported by Agbor M.A. et al. [13] who found $73.4 \%(n=87)$ of cases of gum recession, $59.3 \%(n=71)$ of dental wear lesion, $23.5 \%$ of dental caries $(n=28)$. This result could be explained by the insufficient awareness and information campaigns on the consequences of CT consumption on the tissues of the oral cavity and the delay in consultation.

In the different age groups, the most common oral lesions were observed between 35 - 49 years for the black villous tongue with $17.46 \%(n=11)$. Neoplastic ulcerations were more found between 50 - 64 years old with $12.69 \%(n=8)$. Shukla A. [9] in a study on potentially malignant oral cavity disorders in India found oral submucosal fibrosis in 18 patients (31.03\%). The fibrosis submucosal was more common in patients aged 41 - 50 years and leukoplakia was more observed in the age group of 21 to 30 years with 5 cases (25\%).

\section{Conclusion}

Chewing tobacco predisposes to a high risk of damage to the oral cavity and the development of potentially malignant lesions. In addition, it exerts some detrimental effects on the teeth and adjacent structures. In Guinea, chewing tobacco is consumed and sold in several regions, it constitutes a factor of tobacco intoxication which can be dangerous for the oral cavity. Awareness and education of the population on the harmful effects of chewing tobacco would be necessary to reduce the incidence of oral lesions related to this tobacco and the risks associated with cancer of the oral cavity.

\section{Acknowledgements}

We sincerely thank the staff of the Department of Odontostomatology and Maxillofacial Surgery and the Center for Research and Valorization of Medicinal Plants for the good collaboration during the realization of this study.

\section{Ethical Approval}

The authors obtained the approval of the ethics committee of the University of Conakry to conduct this study. 


\section{Conflicts of Interest}

The authors declare that there is no conflict of interest.

\section{References}

[1] Sieber, A.L., Jeyakumar, J., Bornstein, M.M. and Ramseier, C.A. (2016) Swedish Snuff (Snus) and Its Effects on Oral Health: Update. Swiss Dental Journal, 126, 799-811.

[2] Johnson, N. (2001) Tobacco Use and Oral Cancer: A Global Perspective. Journal of Dental Education, 65, 328-339. https://doi.org/10.1002/j.0022-0337.2001.65.4.tb03403.x

[3] Savitz, D.A., Meyer, R.E., Tanzer, J.M., Mirvish, S.S. and Lewin, F. (2011) Public Health Implications of Smokeless Tobacco Use as a Harm Reduction Strategy. American Journal of Public Health, 96, 19-39. https://doi.org/10.2105/AJPH.2005.075499

[4] Al-Maweri, S., Alaizari, N.A. and Al-Sufyani, G.A. (2014) Oral Mucosal Lesions and Their Association with Tobacco Use and Qat Chewing among Yemeni Dental Patients. Journal of Clinical and Experimental Dentistry, 6, e460-e466. https://doi.org/10.4317/jced.51706

[5] Hallikeri, K., Naikmasur, V., Guttal, K., Shodan, M. and Chennappa, N.K. (2018) Prevalence of Oral Mucosal Lesions among Smokeless Tobacco Usage: A Cross-Sectional Study. Indian Journal of Cancer, 55, 404-409.

https://doi.org/10.4103/ijc.IJC $178 \quad 18$

[6] Muthukrishnan, A. and Warnakulasuriya, S. (2018) Oral Health Consequences of Smokeless Tobacco Use. Indian Journal of Medical Research, 148, 35-40. https://doi.org/10.4103/ijmr.IJMR $1793 \quad 17$

[7] Chaturvedi, P., Arjun, S., Chih-Yen, C. and Warnakulasuriya, S. (2019) Tobacco Related Oral Cancer. The British Medical Journal, 365, 21-42. https://doi.org/10.1136/bmj.12142

[8] Reddy, S.S., Prashanth, R., Devi, B.K.Y., Chugh, N. and Kaur, A. (2015) Thomas N: Prevalence of Oral Mucosal Lesions in Chewing Tobacco Users: A Cross-Sectional Study. Indian Journal of Dental Research, 26, 537-541. https://doi.org/10.4103/0970-9290.172083

[9] Shukla, A. (2014) Potentially Malignant Disorders of the Oral Cavity: A Clinical Study. Indian Journal of Otolaryngology and Head \& Neck Surgery, 66, 79-85. https://doi.org/10.1007/s12070-013-0680-4

[10] Singh, G.P., Rizvi, I., Vivek, G. and Vivek, K.B. (2011) Influence of Smokeless Tobacco on the Periodontal Health Status of the Local Population of Northern INDIA: A Cross-Sectional Study. Dental Research Journal (Isfahan), 8, 211-220.

[11] Sinha, D.N., Gupta, P.C., Ray, C.S. and Singh, P.K. (2012) Prevalence of Smokeless Tobacco Use among Adults in WHO South-East Asia. Indian Journal of Cancer, 49, 342-346. https://doi.org/10.4103/0019-509X.107726

[12] Agrawal, N., Aggarwal, A., Gupta, N.D., Tewari, R.K., Gupta, J. and Garg, A.K. (2021) Oral Health Consequences of Use of Smokeless Tobacco in North India: A Cross-Sectional Survey. Pesquisa Brasileira em Odontopediatria e Clínica Integrada, 21, e0114. https://doi.org/10.1590/pboci.2021.025

[13] Agbor, M.A., Azodo, C.C. and Tefouet, T.S.M. (2013) Smokeless Tobacco Use, Tooth Loss and Oral Health Issues among Adults in Cameroon. African Health Sciences, 13, 785-790. https://doi.org/10.4314/ahs.v13i3.38

[14] Sreeramareddy, C.T., Pradhan, P.M. and Sin, S. (2014) Prevalence Distribution and Social Determinants of Tobacco Use in Sub-Saharan African Countries. BMC Medicine, 12, Article No. 243. https://doi.org/10.1186/s12916-014-0243-X 